\title{
Substance P Promotes Wound Healing in Diabetes by Modulating Inflammation and Macrophage Phenotype
}

\author{
Ermelindo C. Leal, ${ }^{* \dagger}$ Eugénia Carvalho, ${ }^{* \dagger}$ Ana Tellechea, ${ }^{* \dagger}$ Antonios Kafanas, ${ }^{*}$ Francesco Tecilazich, ${ }^{*}$ Cathal Kearney, ${ }^{\ddagger}$ \\ Sarada Kuchibhotla, ${ }^{*}$ Michael E. Auster, ${ }^{*}$ Efi Kokkotou, ${ }^{*}$ David J. Mooney, ${ }^{\star \top}$ Frank W. LoGerfo, ${ }^{*}$ Leena Pradhan-Nabzdyk, ${ }^{*}$ and \\ Aristidis Veves* \\ From the Beth Israel Deaconess Medical Center, * Harvard Medical School, Boston, Massachusetts; the Center for Neuroscience and Cell Biology, ${ }^{\dagger}$ University \\ of Coimbra, Coimbra, Portugal; the Harvard School of Engineering and Applied Sciences, ${ }^{\ddagger}$ Harvard University, Cambridge, Massachusetts; the Department \\ of Anatomy, ${ }^{\S}$ Royal College of Surgeon's in Ireland, Dublin, Ireland; and the Wyss Institute for Biologically Inspired Engineering, ${ }^{\circledR}$ Harvard University, \\ Boston, Massachusetts
}

Accepted for publication

February 24, 2015.

Address correspondence to Aristidis Veves, M.D., Palmer 321A, Beth Israel Deaconess Medical Center, 1 Deaconess Rd., Boston, MA 02215. E-mail: aveves@bidmc. harvard.edu.

\begin{abstract}
Diabetic foot ulceration is a major complication of diabetes. Substance P (SP) is involved in wound healing, but its effect in diabetic skin wounds is unclear. We examined the effect of exogenous SP delivery on diabetic mouse and rabbit wounds. We also studied the impact of deficiency in SP or its receptor, neurokinin-1 receptor, on wound healing in mouse models. SP treatment improved wound healing in mice and rabbits, whereas the absence of SP or its receptor impaired wound progression in mice. Moreover, SP bioavailability in diabetic skin was reduced as SP gene expression was decreased, whereas the gene expression and protein levels of the enzyme that degrades SP, neutral endopeptidase, were increased. Diabetes and SP deficiency were associated with absence of an acute inflammatory response important for wound healing progression and instead revealed a persistent inflammation throughout the healing process. SP treatment induced an acute inflammatory response, which enabled the progression to the proliferative phase and modulated macrophage activation toward the M2 phenotype that promotes wound healing. In conclusion, SP treatment reverses the chronic proinflammatory state in diabetic skin and promotes healing of diabetic wounds. (Am J Pathol 2015, 185: 1638-1648; http://dx.doi.org/10.1016/j.ajpath.2015.02.011)
\end{abstract}

Diabetic foot ulceration is one of the most serious and debilitating complications of diabetes mellitus (DM). ${ }^{1} \mathrm{Pe}$ ripheral neuropathy associated with deficiency of neuropeptides, 2,3 vascular disease, chronic inflammation, increased expression of matrix metalloproteinase (MMP)-9, and aberrant growth factor expression has been associated with diabetic foot ulceration development and failure to heal. ${ }^{4}$

Substance P (SP) belongs to the tachykinin neuropeptide family encoded by the Tacl gene and is one of the main neuropeptides released by $\mathrm{C}$-nociceptive fibers in response to injury. SP exerts its effects mainly via its high-affinity neurokinin-1 receptor (NK1R) and is degraded by the enzyme neutral endopeptidase (NEP). ${ }^{5}$ SP enhances the delivery and accumulation of leukocytes, ${ }^{6}$ induces interleukin (IL)- 8 and IL- $6^{7-9}$ expression, and is mitogenic toward smooth muscle cells, fibroblasts, and endothelial cells. ${ }^{10-12}$ SP promotes wound healing in nondiabetic and diabetic corneal wounds that mainly involve epithelial cells ${ }^{13,14}$ and in nondiabetic cutaneous wounds. ${ }^{15,16}$ However, there is little information regarding its effect in diabetic skin wounds that are characterized by chronic inflammation, neuroischemia, and

\footnotetext{
Supported by NIH grants 1R01NS066205 (A.V. and L.P.-N.) 1R01DK076937 (A.V.), 1R01NS046710 (A.V.), and 1R24DK091210-01 (A.V., F.W.L., and D.J.M.); the European Foundation for the Study of Diabetes, the Juvenile Diabetes Research Foundation, and Novo Nordisk European Programme in Type 1 Diabetes Research (E.C.L. and E.C.), and grants PTDC/SAUFAR/121109/2010 (E.C.L.), SFRH/BPD/46341/2008 (E.C.L.); and SFRH/BD/ 48624/2008 (A.T.) from the Portuguese Foundation for Science and Technology. E.C.L., E.C., and A.T. contributed equally to this work.

Disclosures: None declared.
} 
Table 1 Weight and Blood Glucose Levels in Various Experimental Mice

\begin{tabular}{llllll}
\hline & \multicolumn{2}{l}{ Weight $(\mathrm{g})$} & & \multicolumn{2}{l}{ Blood glucose $(\mathrm{mg} / \mathrm{dL})$} \\
\cline { 2 - 3 } \cline { 5 - 6 } Mouse type & Before diabetes induction & Before wound healing & & Before diabetes induction & Before wound healing \\
\hline WT & $27.1 \pm 0.2$ & $29.0 \pm 0.3^{*}$ & $27.1 \pm 0.2$ & $149.4 \pm 3.3$ & $152.1 \pm 3.4$ \\
DM WT & $27.4 \pm 0.2$ & $29.1 \pm 0.4^{*}$ & $150.6 \pm 3.5$ & $490.1 \pm 8.8^{*}$ \\
NK1RK0 & $27.0 \pm 0.4$ & $25.6 \pm 0.5$ & $147.7 \pm 6.3$ & $152.0 \pm 6.3$ \\
DM NK1RK0 & $26.5 \pm 0.3$ & $29.5 \pm 0.6^{*}$ & $150.9 \pm 5.8$ & $498.2 \pm 11.9^{*}$ \\
TAC1K0 & $27.3 \pm 0.6$ & $26.5 \pm 0.3$ & $149.4 \pm 4.5$ & $152.3 \pm 4.4$ & $4.3 \pm 5.1$ \\
DM TAC1K0 & $27.2 \pm 0.4$ & & 152.3 & $488.5 \pm 9.4^{*}$ \\
\hline
\end{tabular}

Weight and blood glucose levels were measured in control and diabetes mellitus (DM) groups of wild-type (WT) mice, mice deficient in neurokinin-1 receptor (NK1RK0), and mice deficient in the Tac1 gene (TAC1K0) before DM induction and after 8 weeks, before the wound healing experiment. Data are expressed as means \pm SEM of at least 12 animals.

${ }^{*} P<0.001$ for the $t$-test (compared with the initial measurement).

increased expression of MMPs that degrade proteins, including growth factors. ${ }^{4}$

During normal wound healing, macrophages demonstrate transitions in phenotype and function in tissue repair progression, although the factors that regulate these transitions remain poorly defined. Thus, during the inflammatory phase, M1 activated macrophages initiate an acute inflammatory response, whereas during the proliferative phase M2 macrophages promote angiogenesis and granulation tissue formation. ${ }^{17-19}$ Previous studies in our unit have found reduced neuropeptide expression in the skin of diabetic rabbits, which was accompanied by a chronic proinflammatory state, indicated by a high M1/M2 macrophage ratio and an elevated proinflammatory cytokine expression, as well as impaired wound healing. ${ }^{20,21}$ In this study, we investigated the effect of SP in wound healing and related chronic inflammation in wild-type (WT) nondiabetic and diabetic mouse and neuroischemic diabetic rabbit models.

\section{Materials and Methods}

\section{Mouse Model}

We used 16- to 18-week-old male C57BL/6J WT mice, $N k 1 r^{-1-}$ (provided by Dr. Norma Gerard, Children's Hospital, Boston, MA), and $\mathrm{Tacl}^{-1-}$, B6.Cg-Tacl $<\mathrm{tm} 1 \mathrm{Bbm}>/ \mathrm{J}$ ) (Jackson Labs, Bar Harbor, ME). All experiments were approved by Beth Israel Deaconess Medical Center Institutional Animal Care and Use Committee.

\section{Diabetes Mouse Model}

A subset of mice received $50 \mathrm{mg} / \mathrm{kg}$ of streptozotocin in 0.1 $\mathrm{mol} / \mathrm{L}$ citrate buffer by i.p. injection once a day for 5 consecutive days to induce diabetes. The mice with blood glucose levels above $250 \mathrm{mg} / \mathrm{dL}$ were considered diabetic. Wound experiments were performed 8 weeks after diabetes induction. NPH insulin, 0.1 to 0.2 units, was administered as needed to avoid weight loss. Body weight and blood glucose levels were not different between WT and transgenic mice (Table 1).

\section{Wound Healing Model and Treatments}

The mice were anesthetized with $100 \mathrm{mg} / \mathrm{kg}$ of i.p. ketamine and $10 \mathrm{mg} / \mathrm{kg}$ of i.p. Xylazine. After removing the hair from the back of the mice, two 6-mm full-thickness excisional wounds were biopsied. The wound area was traced every day onto acetate paper to follow the rate of wound closure up to 10 days after wounding. The wound size was determined with ImageJ version 1.46r (NIH, Bethesda, MD). The data were presented as a percentage of the original wound (day 0 ). One of the wounds was treated daily with SP $(32 \mu \mathrm{g}$ per wound dissolved in saline), and the other wound was treated with saline until the day of euthanasia. The animals were sacrificed at day 3 or day 10 after wounding.

\section{Diabetic Rabbit Ear Model}

New Zealand White rabbits (3.0 to $3.2 \mathrm{~kg}$; Millbrook Farms, Amherst, MA) were made diabetic for 30 days before a neuroischemic ear wound was created. ${ }^{20,21}$ Briefly, central and rostral arteries were ligated along with central and rostral nerve resection creating the neuroischemia. After surgery, four full-thickness circular wounds were created using a 6-mm punch biopsy. The cartilage was kept intact because it minimizes tissue contracture to $<3 \%$, allowing the wound to heal mostly by reepithelialization. The wound closure was monitored for 10 days. Wounds were either left untreated or treated with $90 \mu \mathrm{L}$ of alginate gel alone or with $32 \mu \mathrm{g}$ per 90 $\mu \mathrm{L}$ of SP. The wounds were photographed using a medical hyperspectral imaging camera (Hypermed Inc., Burlington, MA), and the wound area was measured. All experiments were approved by Beth Israel Deaconess Medical Center Institutional Animal Care and Use Committee.

\section{Tissue Harvesting in Mice}

The skin was collected at day 0 and at the day of sacrifice; the wounds were excised with the wounds margins. For immunohistochemistry (IHC) in paraffin, the tissue was fixed in 10\% formalin and embedded in paraffin, and for gene and/or protein expression, the tissue was snap frozen in 
liquid nitrogen or frozen in optimal cutting temperature compound and kept at $-80^{\circ} \mathrm{C}$.

\section{IHC}

\section{IHC-Paraffin}

Paraffin sections $(5 \mu \mathrm{m})$ were stained with rabbit anti-NEP antibody (Millipore, Billerica, MA). Three separate sections were analyzed from each wound by a masked observer (A.K.) and quantified using two random high-powered fields.

\section{IHC-Frozen}

Frozen skin sections $(5 \mu \mathrm{m})$ were co-stained for detection of M1 macrophages, with CD68 (AbCam, Cambridge, MA) and tumor necrosis factor (TNF)- $\alpha$ (Serotec, Oxford, UK), or for detection of M2 macrophages, with CD68 and CD206 (Santa Cruz Biotechnology, Santa Cruz, CA). The nuclei were stained with DAPI (Sigma, St. Louis, MO). A masked observer (A.K.) counted the number of cells in two random fields using a fluorescent microscope.

\section{Real-Time PCR}

Total RNA was isolated from skin tissue from days 0,3 , and 10 after surgery using an RNeasy Mini Kit (Qiagen, Valencia, CA), following the manufacturer's instructions. cDNA was prepared from $1 \mu \mathrm{g}$ of RNA using the iScript System (BioRad, Hercules, CA). Real-time PCR was performed using Brilliant III Ultra-Fast SYBR Green real-time PCR Master Mix Reagent with a Stratagene MX3000P realtime PCR thermal cycler (Agilent Technologies, Santa Clara, CA). The primer sequences (Table 2) were obtained from Integrated DNA Technologies (Coralville, IA). The gene expression was determined by the ${ }^{\Delta \Delta} \mathrm{CT}$ method of relative quantification obtained as $2^{-\Delta \Delta} \mathrm{CT}$ and normalized to the TATA box binding protein. The data are presented as the fold change over the gene expression in the skin from WT control mice at baseline (day 0).

\section{Western Blot Analysis}

The skin samples were homogenized in T-PER tissue protein extraction reagent (Thermo Scientific, Rockford, IL) supplemented with $1 \mathrm{mmol} / \mathrm{L}$ dithiothreitol (Sigma), phosphatase, and protease inhibitor cocktails (Boston BioProducts, Ashland, MA). Lysates were kept at $4{ }^{\circ} \mathrm{C}$ for 15 minutes and centrifuged at $13,000 \times g$ for 15 minutes, and the supernatant was used for Western blot analysis. The protein content was quantified using the bicinchoninic acid protein assay (Pierce, Rockford, IL) according to the manufacturer's instructions.

The proteins were denatured by adding Laemmli's SDS sample buffer (Boston BioProducts, Ashland, MA) and heating the samples for 5 minutes at $95^{\circ} \mathrm{C}$. Equal amounts of protein, $40 \mu \mathrm{g}$, were resolved by SDS-PAGE using $4 \%$ to $20 \%$ polyacrylamide gels (BioRad). The resultant gels were electrophoretically transferred to polyvinylidene difluoride membranes by a semidry electroblotting system (BioRad). The membranes were blocked for 1 hour at room temperature in Tris-buffered saline containing $0.1 \%$ Tween 20 and 5\% lowfat milk. The incubation with the primary antibodies rabbit anti-MMP-9 (1:2000; Cell Signaling Technology, Danvers, MA) or mouse anti- $\beta$-actin (1:5000; Sigma), was performed overnight at $4^{\circ} \mathrm{C}$. After washing for 1 hour in TBS-T, the membranes were incubated for 1 hour at room temperature with the appropriate antifluorescein alkaline phosphatase conjugate (1:5000; Santa Cruz Biotechnology). Protein signals were detected using the ECF substrate kit (GE HealthCare Life

Table 2 Primers Sequences Used in RT-PCR

\begin{tabular}{|c|c|c|}
\hline Primer & Forward primer & Reverse primer \\
\hline \multicolumn{3}{|l|}{ Mouse } \\
\hline SP & $5^{\prime}-\mathrm{TGGACATGGCCAGATCTCTCACAA-3^{ \prime }}$ & $5^{\prime}$-GCATCGCGCTTCTTTCATAAGCCA-3' \\
\hline NK1R & $5^{\prime}-$ GCCAGAACATCCCAACAGG- $3^{\prime}$ & $5^{\prime}$-GGCGAAGGTACACACAACCA-3' \\
\hline IL-6 & 5'-TGGCTAAGGACCAAGACCATCCAA-3' & 5'-AACGCACTAGGTTTGCCGAGTAGA-3' \\
\hline TNF- $\alpha$ & 5'-TTCCGAATTCAGTGGAGCCTCGAA-3' & 5'-TGCACCTCAGGGAAGAATCTGGAA-3' \\
\hline MMP-9 & $5^{\prime}-$ TССААСТСАСТСАСТGTGGTTGCT-3' & $5^{\prime}$-AGACTGCCAGGAAGACACTTGGTT-3' \\
\hline IL-10 & 5'-CCCTTTGCTATGGTGTCCTTTC-3' & 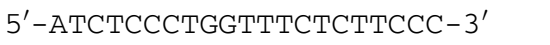 \\
\hline IL-12 & $5^{\prime}-$ CTCAGGATGGAAGAGTCC-3' & 5'-CAAGTGGAATGCTAGAATATC- $3^{\prime}$ \\
\hline IFN- $\gamma$ & 5'-СTTCTTGGATATCTGGAGGAACTG-3' & 5'-GGTGTGATTCAATGACGCTTATG-3' \\
\hline TBP & 5'-АСССТTСАССААТGАСТССТАТG-3' & 5'-TGACTGCAGCAAATCGCTTGG-3' \\
\hline TBP & 5'-TTCCACTCACAGACTCTC-3' & 5'-ACAATCCCAGAACTCTCC-3' \\
\hline
\end{tabular}

IFN- $\gamma$, interferon- $\gamma ; \mathrm{KC}$, skin keratinocyte-derived cytokine; MCP-1, monocyte chemoattractant protein-1; MMP-9, matrix metalloproteinase-9; NEP, neutral endopeptidase; NK1R, neurokinin receptor-1; SP, substance P; TBP, TATA box binding protein; TNF- $\alpha$, tumor necrosis factor- $\alpha$. 
A
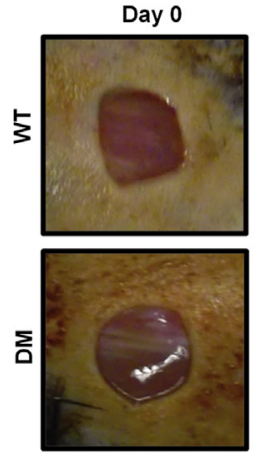

B

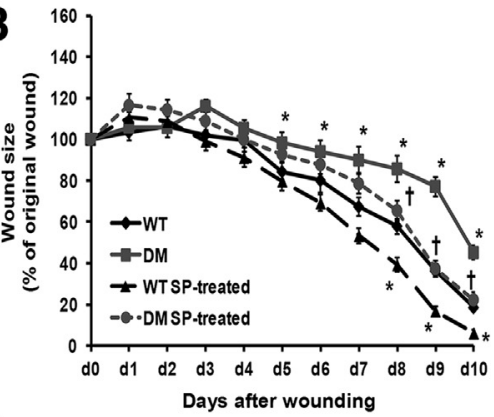

D

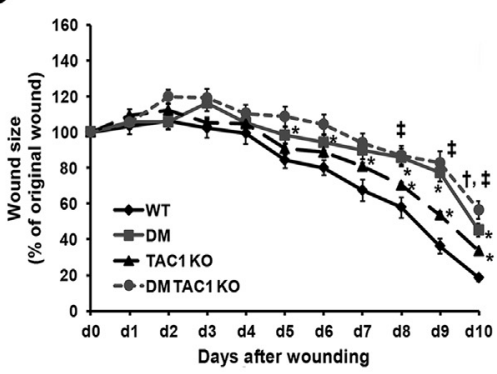

Day 10
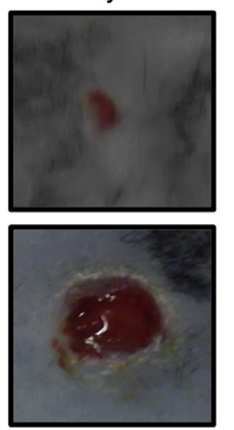

C

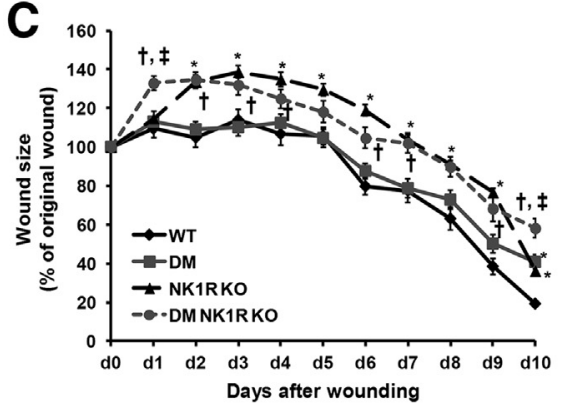

Day 10
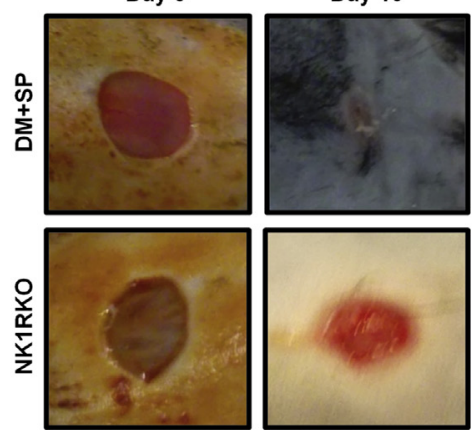

E

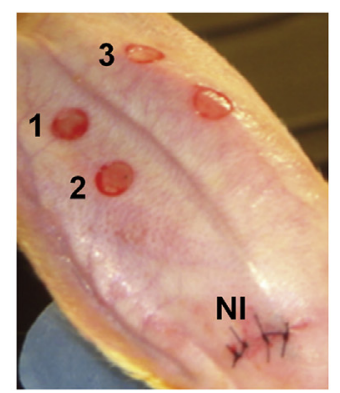

Figure 1 Substance $P$ (SP) plays an important role in wound healing. A: Representative images of the wounds at baseline (day 0) and day 10 of wild-type (WT) nondiabetic mice, WT mice with diabetes mellitus (DM), WT diabetic SP-treated wound (DM + SP) mice, and mice deficient in neurokinin-1 receptor (NK1RKO). B: SP accelerates wound closure in WT and DM mice. C: Non-DM and DM NK1RKO mice have delayed wound closure. D: Non-DM and DM mice deficient in the Tac1 gene (TAC1KO) have delayed wound closure. E: Neuroischemia (NI) wound healing rabbit model. 1, Untreated; 2, vehicle; and 3, SP. F: SP improved wound healing in an NI diabetic rabbit wound healing model. Data are presented as the percentage of the original wound and expressed as means \pm SEM of at least eight animals. ${ }^{*} P<0.05,{ }^{*} P<0.01$ versus DM NI untreated; ${ }^{\dagger} P<0.05$ compared with DM; ${ }^{\ddagger} P<0.05$ compared to NK1RK0 or TAC1KO for one-way analysis of variance followed by Fisher's post hoc test.

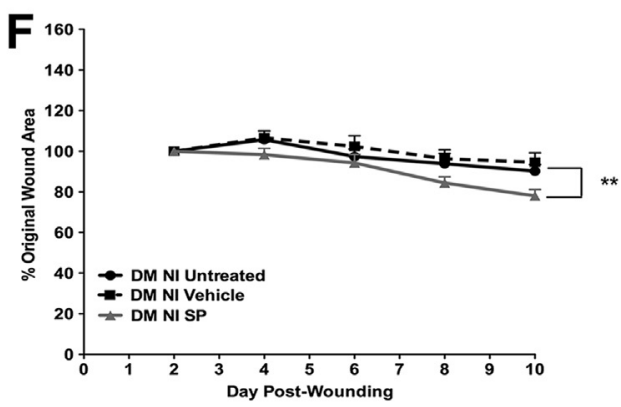

Sciences, Pittsburgh, PA), as described in the manufacturer's instructions. The membrane was visualized using a VersaDoc imaging system (model 3000; BioRad), and the band density was evaluated with the Quantity One version 4.5.2 (BioRad). Protein quantification was normalized with actin.

\section{Multiplex Serum Analysis}

Immediately after collection, blood was centrifuged at $20,000 \times g$, at $4^{\circ} \mathrm{C}$ for 20 minutes. Serum was then collected and stored at $-80^{\circ} \mathrm{C}$ until analysis. Serum protein levels of inflammatory cytokines and biochemical markers of endothelial function were measured using a Luminex 200 apparatus (Luminex, Austin, TX) and Millipore multiplex immunoassay panels (Millipore, Chicago, IL).

\section{Statistical Analysis}

The statistical analysis was performed using Minitab (Minitab, State College, PA). Differences among experimental groups were analyzed using the $t$-test or the one-way analysis of variance followed by Fisher's post hoc test. The results are expressed as means \pm SEM.

\section{Results}

SP Treatment Improves Wound Healing in the Diabetic Mouse and Rabbit Models

WT diabetic mice had impaired wound healing when compared with WT nondiabetic mice after day 5 after wounding (Figure 1, A and B). SP treatment accelerated wound closure from day 8 to day 10 in both WT nondiabetic and diabetic mice (Figure 1B). In addition, SP treatment significantly reduced rabbit diabetic neuroischemic wound size, which mimics the neuropathy and ischemia common to human diabetic foot ulcerations (Figure 1, E and F). These results suggest that pharmacological levels of SP improve wound healing in diabetes.

\section{The Absence of SP or Its Receptor Affects Wound Healing}

To further investigate the role of SP in wound healing, we used two genetically modified mouse models: mice deficient in NK1R (NK1RKO mice; official name Tacrl) and 

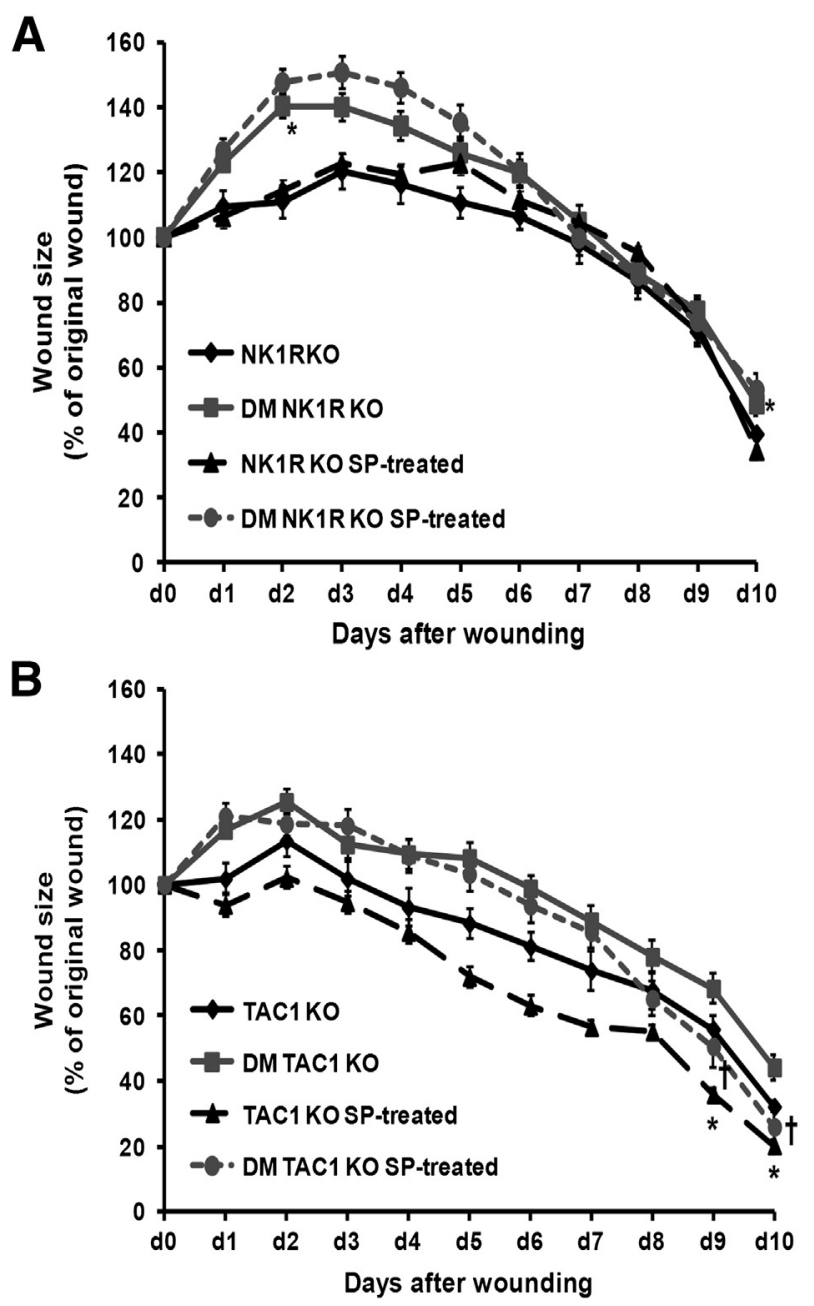

Figure 2 Substance $P(S P)$ acts mainly through the neurokinin 1 receptor (NK1R). The lack of SP or its NK1R delays dermal repair. A: SP treatment does not alter wound closure progression in mice deficient in neurokinin-1 receptor (NK1RKO mice). B: SP treatment accelerates wound closure in mice without diabetes mellitus (DM) and DM mice deficient in the Tac1 gene (TAC1K0). Data are expressed as means \pm SEM of at least 12 animals. ${ }^{*} P<0.05$ compared with NK1RKO or TAC1K0; ${ }^{\dagger} P<0.05$ compared with DM NK1RKO or DM TAC1KO mice for one-way analysis of variance followed by Fisher's post hoc test.

mice deficient in the Tacl gene that encodes for SP and other tachykinins (TAC1KO mice). Both nondiabetic and diabetic NK1RKO and TAC1KO mice had impaired wound healing throughout the 10-day experimental period when compared with their respective WT controls (Figure 1, C and D).

\section{NK1R Mediates the Effect of SP in Wound Healing}

To evaluate whether the effect of SP in wound healing was mediated mainly by NK1R rather than NK2R or NK3R, SP was applied to the wounds of NK1RKO mice. SP did not change wound closure kinetics in NK1RKO mice (Figure 2A). SP accelerated wound closure in both nondiabetic and diabetic TAC1KO mice (Figure 2B), suggesting that $\mathrm{SP}$ is the main
A

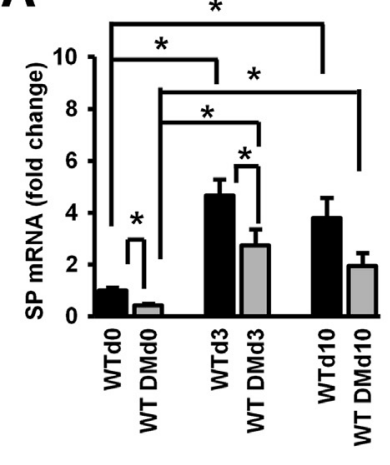

C
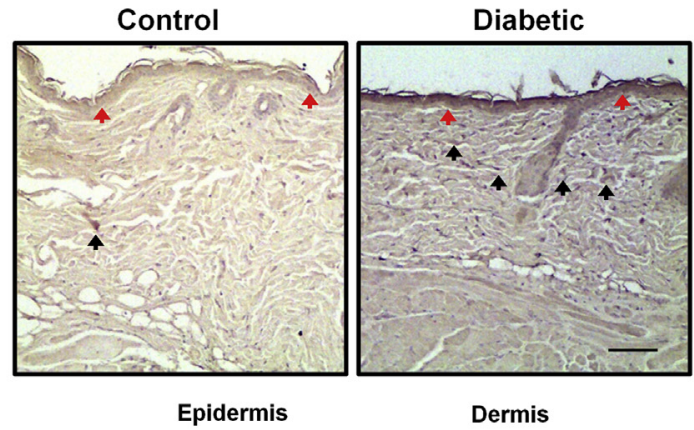

D

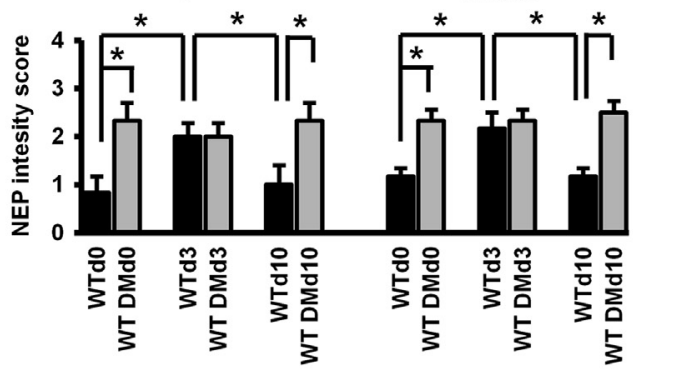

E

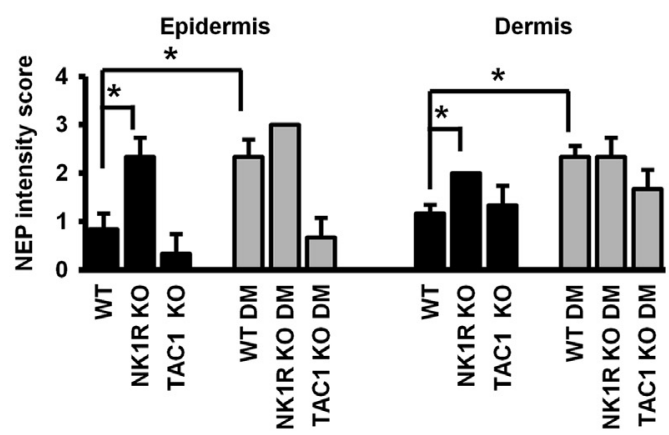

Figure 3 Substance $\mathrm{P}(\mathrm{SP})$ skin expression is reduced in diabetes mellitus (DM), whereas neurokinin receptor-1 (NK1R) and neutral endopeptidase (NEP) expression is increased. SP $(\mathbf{A})$ and NEP (B) gene expression. C: NEP staining at baseline (day 0 ) in skin of wild-type (WT) and WT DM mice. DM mice have a higher NEP intensity in the epidermis (red arrows) and higher number of NEP-positive cells in dermis (black arrows) compared with WT non-DM mice at day 0. NEP staining is cytoplasmic. D and E: Quantification of NEP levels. Data are presented as fold change over the WT mice without diabetes mellitus (DM) mice at baseline (A and B); in the epidermis, as a score of intensity: 0 for faint or absent, 1 for low, 2 for moderate, and 3 for high ( $\mathbf{D}$ and $\mathbf{E}$ ); and in the dermis, as a score of cell percentage: 1 for $0 \%$ up to $20 \%$ positive cells, 2 for $20 \%$ up to $60 \%$, and 3 when $>60 \%$ of positive cells ( $\mathbf{D}$ and $\mathbf{E}$ ). Data are expressed as means \pm SEM of eight animals ( $\mathbf{A}$ and $\mathbf{B}$ ) and means \pm SEM of six animals ( $\mathbf{D}$ and $\mathbf{E}$ ). ${ }^{*} P<0.05$ compared with WT non-DM mice for one-way analysis of variance followed by Fisher's post hoc test. Scale bar $=100 \mu \mathrm{m}(\mathbf{C})$. Original magnification: $\times 100(\mathbf{C})$. 
tachykinin expressed by the Tacl gene involved in the wound healing process.

\section{SP Gene Expression Is Reduced in Diabetic Skin}

At baseline, $S P$ gene expression was lower in the skin of WT diabetic than WT nondiabetic mice. When compared with baseline, $S P$ gene expression was increased in WT nondiabetic mice at day 3 and day 10 after wounding (Figure 3A). A similar but not as pronounced response was observed in the WT diabetic mice. Diabetic NK1RKO mice had higher SP expression than WT diabetic mice at day 0 and day 10 (Supplemental Figure S1A). Local SP treatment of WT nondiabetic wounds reduced $S P$ gene expression at day $10 . N k 1 r$ gene expression at day 0 was increased in diabetic TAC1KO mice when compared with their WT controls (Supplemental Figure S1B). These results indicate that SP skin expression is reduced in diabetes during all phases of wound healing, whereas there is a compensatory increase in mice with deficiency in NK1R.

NEP Gene and Protein Expression Is Increased in the Skin of WT Diabetic and NK1RKO Mice but Not in TAC1K0 Mice

At baseline, the gene and protein skin expression of NEP, the enzyme that breaks down SP, was increased in WT diabetic mice and in both nondiabetic and diabetic NK1RKO mice (Figure 3, B-E).

In WT nondiabetic wounds, NEP levels increased at day 3 but returned to prewounding levels by day 10. In contrast, in WT diabetic mice, NEP levels remained elevated at day 10 , indicating that this is an additional factor leading to reduced SP bioavailability.

\section{SP Promotes the Acute Inflammatory Response to Skin Injury}

In WT nondiabetic mice, the IL-6 gene (Il6) expression peaked at day 3 and returned to baseline levels at day 10, but in WT diabetic mice it was persistently increased (Figure 4A). SP treatment further increased day 3 Il6 gene expression in WT nondiabetic mice and reduced it at day 10 in WT diabetic mice. A pronounced increase in $I l 6$ gene expression was also observed in both nondiabetic and diabetic NK1RKO and TAC1KO mice at baseline when compared with their respective WT controls (Figure 4B). Similar results were observed for skin keratinocyte-derived cytokine (KC), the mouse homolog for human IL-8 (Supplemental Figure S2, A and B), and TNF- $\alpha$ gene (Tnfa) expression (Supplemental Figure S2, C and D).

Serum IL-6 levels were increased in the diabetic NK1RKO and diabetic TAC1KO mice at baseline compared with WT diabetic mice (Figure 4C). At day 3, IL-6 circulating levels increased in all phenotypes compared with baseline. Of interest, at day 10, IL-6 levels remained increased in WT diabetic and NK1RKO diabetic mice, whereas levels returned to baseline in all other conditions. Similarly, higher levels of $\mathrm{KC}$, granulocyte colony-stimulating factor, and the tissue plasminogen activator inhibitor-1 were observed in WT diabetic and/or transgenic mice (Supplemental Figure S3).

The above results indicate that diabetes and deficiency of SP or its receptor are associated with a chronic low-grade inflammation before wounding, an inability to mount a robust acute inflammatory response in the early stages of wound healing, and a persistence of low-grade inflammation at the later phases of
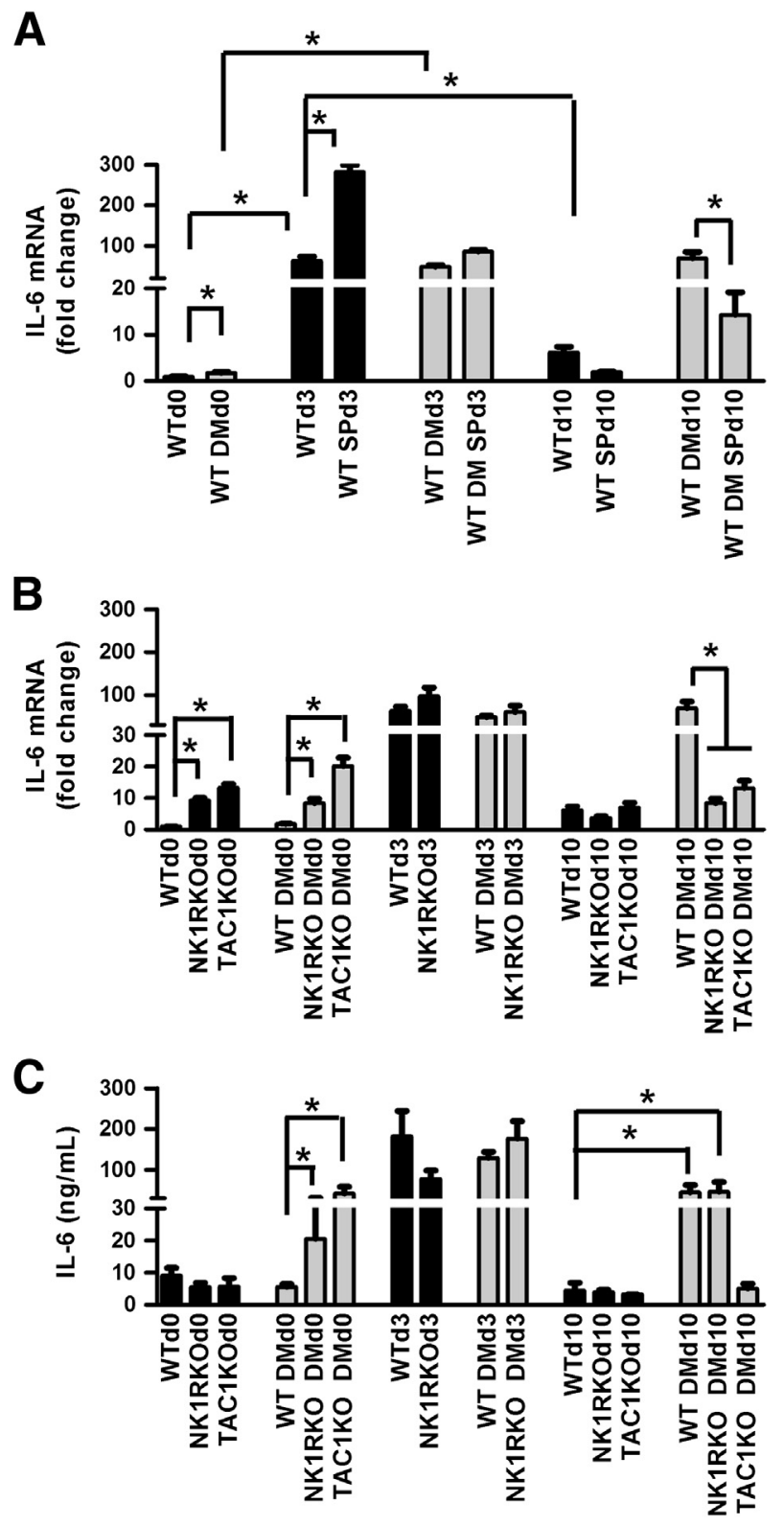

Figure 4 Substance $P(S P)$ promotes the acute inflammatory phase of wound healing. Il6 gene expression in wild-type (WT) (A) and mice deficient in neurokinin-1 receptor (NK1RKO) and mice deficient in the Tac1 gene (TAC1K0) (B). C: IL-6 serum levels. The gene expression data are presented as fold change over the WT mice without diabetes mellitus (DM) at baseline and are expressed as means \pm SEM of eight animals ( $\mathbf{A}$ and $\mathbf{B})$. Data represent the means \pm SEM of at least eight animals (C). ${ }^{*} P<0.05$ for one-way analysis of variance followed by Fisher's post hoc test (comparisons represented in the figure). 
A
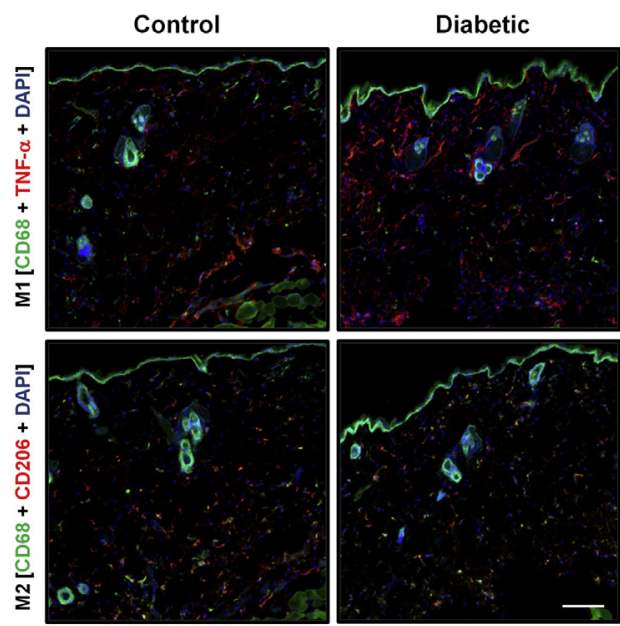

D

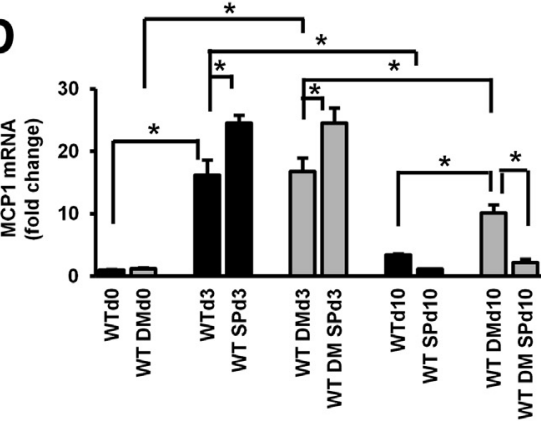

B
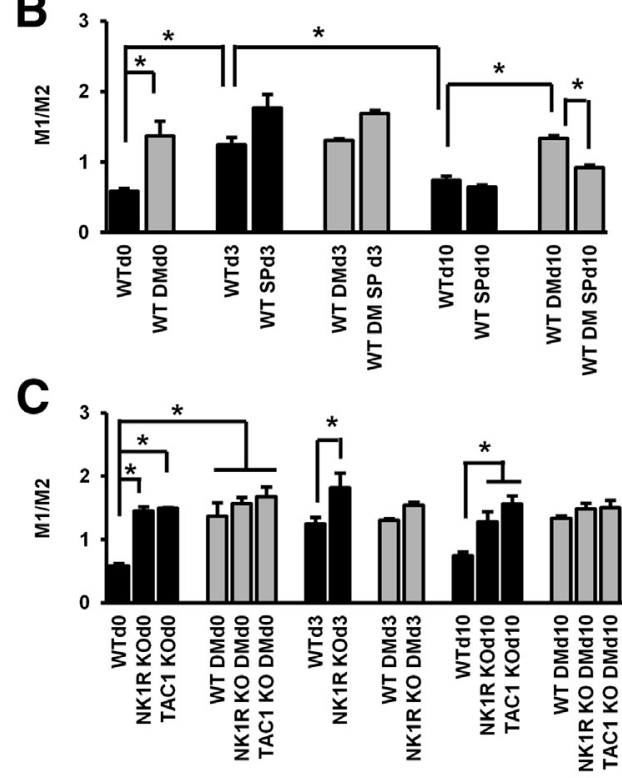

$\mathbf{E}$

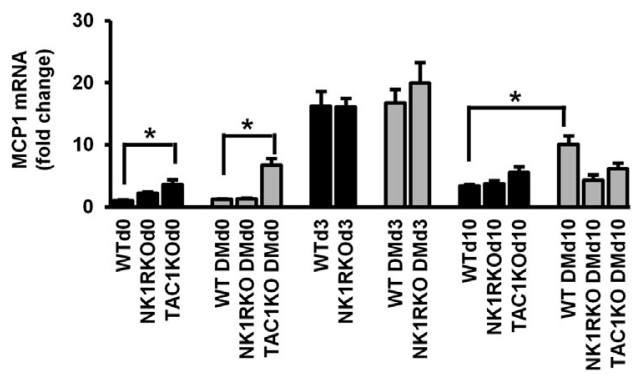

Figure 5 Substance $\mathrm{P}(\mathrm{SP})$ regulates macrophage function during wound healing. A: $\mathrm{M} 1$ and $\mathrm{M} 2$ representative images in control and diabetic mouse skin at baseline. M1/M2 ratio in wild-type (WT) (B) and mice deficient in neurokinin-1 receptor (NK1RK0) and mice deficient in the Tac1 gene (TAC1K0) (C). The M1/M2 ratio represents the means \pm SEM of six to eight animals. MCP1 skin gene expression was evaluated in WT (D) and NK1RKO and TAC1K0 (E) mice. The gene expression data are presented as fold change over the WT mice without diabetes mellitus (DM) at baseline and expressed as means \pm SEM of eight animals, ${ }^{*} P<0.05$ for one-way analysis of variance followed by Fisher's post hoc test (comparisons represented in the figure). Original magnification: $\times 100(\mathbf{A})$. Scale bar $=100 \mu \mathrm{m}(\mathbf{A})$.

healing. SP treatment promotes an acute inflammatory response that enables progression to the proliferative phase.

\section{SP Modulates Macrophage Phenotype during Wound Healing}

We evaluated the M1 and M2 macrophage polarization in wound healing progression and calculated the M1/M2 ratio that best reflects the inflammatory state of the wound (Figure 5 and Supplemental Figure S4). Diabetes increased the skin M1/M2 ratio at baseline (Figure 5B). In WT nondiabetic mice, the ratio increased at day 3 and returned to baseline levels by day 10 , whereas there were no postwounding changes in WT diabetic mice. At day 10, SP treatment reduced the diabetes-induced high M1/M2 ratio. Similarly to WT diabetic mice, nondiabetic and diabetic NK1RKO and TAC1KO mice had a persistent high M1/M2 ratio through wound healing progression (Figure $5 \mathrm{C}$ ).

The gene expression of the monocyte chemoattractant protein (MCP)-1, which recruits monocytes to areas of inflammation where they are differentiated to macrophages, was increased at day 3 in WT nondiabetic and diabetic mice when compared with day 0 . At day 10, MCP-1 skin expression was significantly reduced in WT nondiabetic and diabetic mice when compared with respective day 3 . However, MCP-1 expression was significantly higher in WT diabetic mice when compared with WT nondiabetic mice at day 10 (Figure 5D). SP treatment increased MCP-1 expression at day 3 and reduced it at day 10 in both WT nondiabetic and diabetic wounds. TAC1KO nondiabetic and diabetic mice exhibited higher $M C P 1$ gene expression at day 0 when compared with WT control and WT diabetic wounds, respectively (Figure 5E).

We also evaluated the skin gene expression of IL-12 and interferon IFN)- $\gamma$ that promote M1 activation and of IL-10 that promotes M2 activation. SP treatment increased IL-12 expression in WT diabetic wounds at day 3 (Supplemental Figure S5A). IL-12 was elevated in nondiabetic and diabetic NK1RKO and TAC1KO mice at day 0 and in diabetic NK1RKO and TAC1KO mice at day 10 (Supplemental 

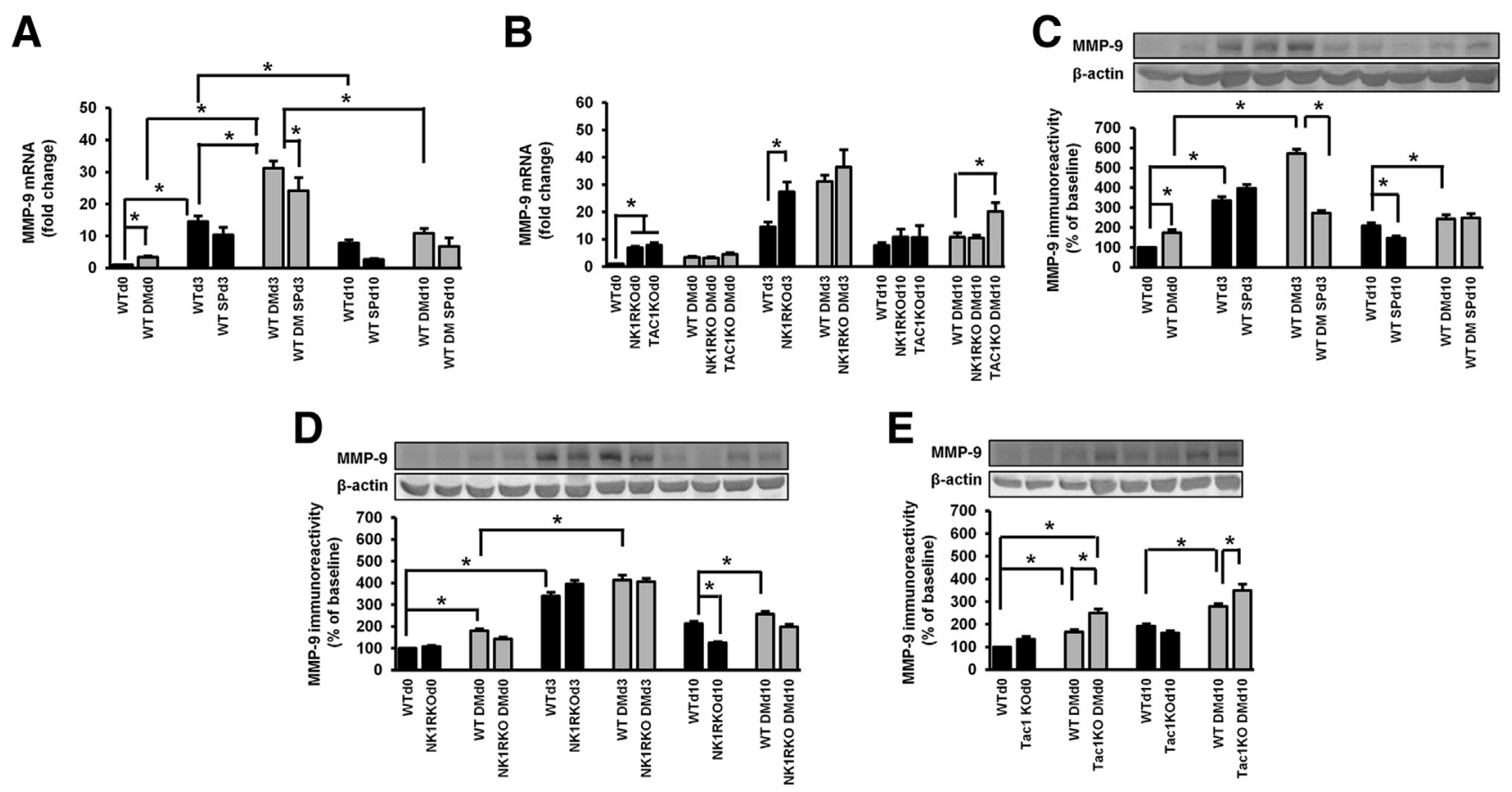

Figure 6 Diabetes mellitus (DM), substance P (SP) deficiency, and neurokinin-1 receptor (NK1R) deficiency increase matrix metalloproteinase (MMP)-9 skin expression. SP treatment reduces MMP-9 skin expression in DM. MMP-9 skin gene expression in wild-type (WT) (A) and mice deficient in neurokinin-1 receptor (NK1RK0) and mice deficient in the Tac1 gene (TAC1K0) (B). MMP-9 protein levels in WT (C), NK1RKO (D), and TAC1K0 (E) mice. The protein levels are presented as the densitometry of MMP-9 relative to $\beta$-actin. The gene expression data are presented as fold change over the WT mice at baseline and expressed as means \pm SEM of eight animals ( $\mathbf{A}$ and $\mathbf{B}$ ). The data represent the percentage of MMP-9 protein level at baseline and are expressed as means \pm SEM of eight animals (C-E). ${ }^{*} P<0.05$ for one-way analysis of variance followed by Fisher's post hoc test (comparisons represented in the figure).

Figure S5B). Similar results were observed in IFN- $\gamma$ and IL10 (Supplemental Figure S5, C-F). These results indicate that, similar to diabetes, SP or NK1R deficiency results in proinflammatory activation of skin macrophages before wounding. SP treatment plays a major role in shifting macrophages to the M2 phenotype, promoting wound healing during the proliferative phase. Furthermore, SP increases the expression of MCP-1 during the early stages of wound healing but reduces it in the later stages.

\section{MMP-9 Skin Expression Is Increased in Diabetic and SP or NK1R Deficient Mice, Whereas SP Reduces MMP-9 Wound Expression}

At day 0, skin $M m p 9$ gene expression was increased in the WT diabetic mice (Figure 6A). At day 3, both WT nondiabetic and diabetic mice had increased Mmp9 expression compared with baseline. However, this increase was higher in diabetic wounds. SP treatment reduced $\mathrm{Mmp} 9$ expression in the diabetic wounds at day 3. Mmp9 skin gene expression was increased at day 0 in nondiabetic NK1RKO and TAC1KO mice when compared with WT control wounds (Figure 6B).

Similar results were found regarding MMP-9 protein skin expression. Thus, MMP-9 protein was increased in WT diabetic mice at day 0 . It increased from baseline at day 3 in both WT nondiabetic and diabetic mice and returned to lower levels at day 10 (Figure 6C). However, at day 10,
MMP-9 protein expression was higher in WT diabetic than in WT nondiabetic wounds, whereas SP treatment further reduced it in the WT nondiabetic mice. NK1RKO wounds had a decrease in MMP-9 levels at day 10 compared with WT nondiabetic wounds (Figure 6D). In contrast, diabetic TAC1KO wounds had an increase at day 3 and day 10 when compared with WT diabetic wounds (Figure 6E). The above results indicate that deficiency in SP or its receptor leads to chronically elevated skin MMP-9 expression, whereas SP treatment reduces it.

\section{Discussion}

Normal wound healing is divided into three phases with limited overlap: coagulation-inflammation, proliferation, and remodeling. ${ }^{22-24}$ In diabetic foot ulceration, this linear progression from one phase to the next is absent, resulting in persistence of a chronic proinflammatory state that is present most of the wound area. ${ }^{22,25,26}$ Previous studies have found that SP can improve acute skin wound healing in nondiabetic $^{16}$ and corneal healing in nondiabetic and diabetic animals. ${ }^{14}$ However, its effect on diabetic skin wounds, where a deficient interplay of multiple cell types and chronic proinflammatory environment persist, has not been investigated. Our results indicate that SP improves cutaneous wound healing mainly by acting during the inflammatory phase, when it increases the local and systemic expression of IL-6, KC (mouse equivalent of human IL-8), and other 
inflammatory cytokines that are known to play a pivotal role in this phase. ${ }^{27}$ Furthermore, SP treatment reduced the expression of these proinflammatory cytokines at day 10 , clearly indicating resolution of inflammation and progression to the proliferative phase. On the other hand, lack of SP and/ or its receptor, in TAC1KO and NK1RKO mice, respectively, had effects similar to diabetes, namely, increased basal cytokine expression, inability to mount a robust acute inflammatory response at day 3 , and persistence of a low-grade proinflammatory state by day 10 . This is, to the best of our knowledge, the first study to find that lack of SP is associated with the chronic proinflammatory state and the failure to mount an adequate acute inflammatory response to injury that occur in diabetes.

We also present evidence that SP affects macrophage activation phenotype during the various phases of wound healing. Studies have found that manipulating the phenotype of endogenous macrophages may be a promising therapeutic option for improving tissue repair. ${ }^{28,29}$ In nondiabetic mice, the M1/M2 ratio peaked at day 3 and returned to baseline levels at day 10, suggesting progression to the proliferative phase of healing. In contrast, and in similarity with the proinflammatory cytokine profile, the baseline $\mathrm{M} 1 / \mathrm{M} 2$ ratio was increased in WT diabetic mice and in NK1RKO and TAC1KO mice. A similar M1 polarization, which is associated with a chronic proinflammatory state, has also been reported in chronic venous ulcers. ${ }^{30} \mathrm{SP}$ treatment at day 10 reduced the M1/M2 ratio in the WT diabetic mice and had a similar effect on MCP-1 skin expression, which is implicated in macrophage recruitment in adipose tissue. ${ }^{18,31} \mathrm{~A}$ possible mechanism of action of SP is by reducing oxidative stress. In the presence of increased oxidative stress, macrophages tend to adopt a more proinflammatory phenotype. ${ }^{32}$ In addition, SP reduces oxidative stress in corneal wound healing. ${ }^{33}$ In our mouse model, the skin proinflammatory condition at baseline in WT diabetic mice and in NK1RKO and TAC1KO mice was also associated with an elevated M1/M2 ratio. Thus, it is possible that substance $\mathrm{P}$ leads to a reduction in oxidative stress along with a decrease in inflammatory markers and consequently to a polarization toward the M2 phenotype. However, additional studies will be required to further investigate this mechanism.

SP treatment also affected the skin expression of MMP-9, an extracellular protein that is involved in the breakdown of matrix proteins and growth factors. ${ }^{22}$ Timely expression of MMP-9 and other matrix metalloproteinases promotes healing in acute wounds and other inflammatory conditions, ${ }^{34-39}$ and our data suggest that SP plays an important role in this pathway.

An additional important finding is that in nonwounded kin, NK1RKO and TAC1KO mice mimicked the chronic proinflammatory state that was present in the skin of WT diabetic mice, including increased IL- 6 , KC, TNF- $\alpha$, MMP9, M1 macrophages, and M1/M2 ratio. These findings suggest that SP deficiency may be a major factor in promoting the chronic proinflammatory state in diabetes.
There is currently no satisfactory animal model of diabetic wound healing, and the current consensus it that more than one animal model should be studied for reliable results. We confirmed our mouse findings in the neuroischemic diabetic rabbit ear model that heals with minimal contraction, is characterized by chronic inflammation and increased baseline M1/ M2 ratio, ${ }^{21}$ and is probably the closest animal model to the human neuroischemic diabetic foot ulceration. ${ }^{3,20,21}$ Because SP had a similar effect in both mouse and rabbit models, we believe that they satisfactorily represent the human condition and that the data support the progression to phase $1 / 2$ clinical trials.

This study has its limitations. We studied only animal models of type 1 diabetes. However, there are no differences in diabetic foot ulceration pathophysiology and natural history between human type 1 and type 2 diabetes, whereas the chosen models allowed us to study the effect of diabetes in the transgenic mice. In addition, we did not apply splinting in the mouse wounds to influence possible healing by contraction because previous studies found that modulation of extracellular and intracellular tension may inadvertently affect wound healing. ${ }^{40}$ In addition, in our studies the wound size of diabetic mice tended to increase the first 3 days, indicating reduced contraction. Furthermore, the confirmation of the observed results in the rabbit model that heals mainly by reepithelialization with minimal contraction clearly indicates that the lack of splinting was not a major factor for the observed results.

Our findings suggest mechanisms related to impaired wound healing in diabetes that are depicted in Figure 7 and

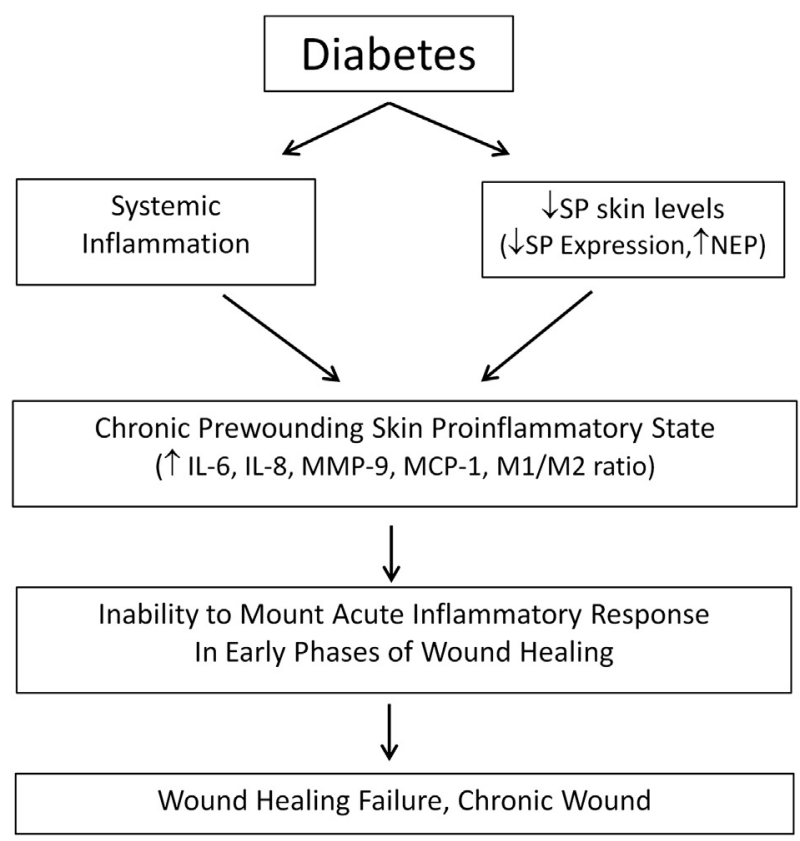

Figure 7 Mechanisms of impaired wound healing in diabetes. Systemic inflammation and reduced substance $P(S P)$ skin bioavailability result in a chronic skin proinflammatory state that leads to the inability to mount an acute inflammatory response, culminating in failure to heal and development of a chronic wound. MCP-1, monocyte chemoattractant protein-1; MMP-9, matrix metalloproteinase-9; NEP, neutral endopeptidase. 
can lead to the development of new diabetic foot ulceration treatments. Thus, systemic inflammation and reduced SP skin bioavailability result in a chronic skin proinflammatory state that results in the inability to mount an acute inflammatory response, leading to healing failure and the development of a chronic wound. NEP inhibitors have been proposed as possible treatments, but their use is hampered by the fact that they result in hydrolysis of a large number of peptides and are associated with serious adverse effects, such as angioedema. ${ }^{41,42}$ However, local treatment with SP or SP analogs has the potential not only to promote diabetic foot ulceration healing but also to reverse the chronic proinflammatory state present in diabetic skin without major adverse effects expected.

\section{Acknowledgments}

We thank Dr. Norma Gerard (Children's Hospital, Boston, MA) for providing the NK1RKO mice. A.V. was responsible for study concept, design, and initial data analysis; A.V. and E.C.L. wrote the manuscript; E.C.L, E.C., A.T., F.T., S.K., M.E.A, E.K., D.J.M., C.K., F.W.L., and L.P.-N. collected data; C.K. prepared the alginate gels; and A.K. analyzed the skin biopsy results. All authors analyzed and interpreted the data and reviewed and approved the final manuscript. A.V. is the guarantor of this work and, as such, had full access to all data reported in the study and takes responsibility for the integrity of the data and the accuracy of the data analysis.

\section{Supplemental Data}

Supplemental material for this article can be found at http://dx.doi.org/10.1016/j.ajpath.2015.02.011.

\section{References}

1. American Diabetes Association: Vital Statistics. Alexandria, VA: Diabetes, 1996, pp 31

2. Pavlovic S, Daniltchenko M, Tobin DJ, Hagen E, Hunt SP, Klapp BF, Arck PC, Peters EM: Further exploring the brain-skin connection: stress worsens dermatitis via substance P-dependent neurogenic inflammation in mice. J Invest Dermatol 2008, 128:434-446

3. Pradhan L, Nabzdyk C, Andersen ND, LoGerfo FW, Veves A: Inflammation and neuropeptides: the connection in diabetic wound healing. Expert Rev Mol Med 2009, 11:e2

4. Dinh T, Tecilazich F, Kafanas A, Doupis J, Gnardellis C, Leal E, Tellechea A, Pradhan L, Lyons TE, Giurini JM, Veves A: Mechanisms involved in the development and healing of diabetic foot ulceration. Diabetes 2012, 61:2937-2947

5. Olerud JE, Usui ML, Seckin D, Chiu DS, Haycox CL, Song IS, Ansel JC, Bunnett NW: Neutral endopeptidase expression and distribution in human skin and wounds. J Invest Dermatol 1999, 112: 873-881

6. Pernow B: Substance P. Pharmacol Rev 1983, 35:85-141

7. Dallos A, Kiss M, Polyanka H, Dobozy A, Kemeny L, Husz S: Effects of the neuropeptides substance $\mathrm{P}$, calcitonin gene-related peptide, vasoactive intestinal polypeptide and galanin on the production of nerve growth factor and inflammatory cytokines in cultured human keratinocytes. Neuropeptides 2006, 40:251-263

8. Tokuda M, Miyamoto R, Sakuta T, Nagaoka S, Torii M: Substance $\mathrm{P}$ activates p38 mitogen-activated protein kinase to promote IL-6 induction in human dental pulp fibroblasts. Connect Tissue Res 2005, 46:153-158

9. Schratzberger P, Reinisch N, Prodinger WM, Kahler CM, Sitte BA, Bellmann R, Fischer-Colbrie R, Winkler H, Wiedermann CJ: Differential chemotactic activities of sensory neuropeptides for human peripheral blood mononuclear cells. J Immunol 1997, 158:3895-3901

10. Nilsson J, von Euler AM, Dalsgaard CJ: Stimulation of connective tissue cell growth by substance $\mathrm{P}$ and substance K. Nature 1985, 315:61-63

11. Ziche M, Morbidelli L, Pacini M, Geppetti P, Alessandri G, Maggi CA: Substance P stimulates neovascularization in vivo and proliferation of cultured endothelial cells. Microvasc Res 1990, 40:264-278

12. Rameshwar P, Poddar A, Zhu G, Gascon P: Receptor induction regulates the synergistic effects of substance P with IL-1 and platelet-derived growth factor on the proliferation of bone marrow fibroblasts. J Immunol 1997, 158:3417-3424

13. Hong HS, Lee J, Lee E, Kwon YS, Lee E, Ahn W, Jiang MH, Kim JC, Son Y: A new role of substance $\mathrm{P}$ as an injury-inducible messenger for mobilization of CD29(+) stromal-like cells. Nat Med 2009, 15:425-435

14. Nakamura M, Kawahara M, Morishige N, Chikama T, Nakata K, Nishida T: Promotion of corneal epithelial wound healing in diabetic rats by the combination of a substance P-derived peptide (FGLM-NH2) and insulin-like growth factor-1. Diabetologia 2003, 46:839-842

15. Kant V, Gopal A, Kumar D, Bag S, Kurade NP, Kumar A, Tandan SK, Kumar D: Topically applied substance P enhanced healing of open excision wound in rats. Eur J Pharmacol 2013, 715:345-353

16. Jing C, Jia-Han W, Hong-Xing Z: Double-edged effects of neuropeptide substance $P$ on repair of cutaneous trauma. Wound Repair Regen 2010, 18:319-324

17. Gordon S, Martinez FO: Alternative activation of macrophages: mechanism and functions. Immunity 2010, 32:593-604

18. Sica A, Mantovani A: Macrophage plasticity and polarization: in vivo veritas. J Clin Invest 2012, 122:787-795

19. Lucas T, Waisman A, Ranjan R, Roes J, Krieg T, Muller W, Roers A, Eming SA: Differential roles of macrophages in diverse phases of skin repair. J Immunol 2010, 184:3964-3977

20. Pradhan L, Cai X, Wu S, Andersen ND, Martin M, Malek J, Guthrie P, Veves A, Logerfo FW: Gene expression of pro-inflammatory cytokines and neuropeptides in diabetic wound healing. J Surg Res 2011, 167: 336-342

21. Pradhan Nabzdyk L, Kuchibhotla S, Guthrie P, Chun M, Auster ME, Nabzdyk C, Deso S, Andersen N, Gnardellis C, LoGerfo FW, Veves A: Expression of neuropeptides and cytokines in a rabbit model of diabetic neuroischemic wound healing. J Vasc Surg 2013, 58:766-775.e12

22. Falanga V: Wound healing and its impairment in the diabetic foot. Lancet 2005, 366:1736-1743

23. Singer AJ, Clark RA: Cutaneous wound healing. N Engl J Med 1999, 341:738-746

24. Santoro MM, Gaudino G: Cellular and molecular facets of keratinocyte reepithelization during wound healing. Exp Cell Res 2005, 304:274-286

25. Loots MA, Lamme EN, Zeegelaar J, Mekkes JR, Bos JD, Middelkoop E: Differences in cellular infiltrate and extracellular matrix of chronic diabetic and venous ulcers versus acute wounds. J Invest Dermatol 1998, 111:850-857

26. Brem H, Tomic-Canic M: Cellular and molecular basis of wound healing in diabetes. J Clin Invest 2007, 117:1219-1222

27. Gallucci RM, Simeonova PP, Matheson JM, Kommineni C, Guriel JL, Sugawara T, Luster MI: Impaired cutaneous wound healing in interleukin-6-deficient and immunosuppressed mice. FASEB J 2000, $14: 2525-2531$

28. Goren I, Muller E, Schiefelbein D, Christen U, Pfeilschifter J, Muhl H, Frank S: Systemic anti-TNFalpha treatment restores diabetes-impaired skin repair in ob/ob mice by inactivation of macrophages. J Invest Dermatol 2007, 127:2259-2267 
29. Mirza RE, Fang MM, Ennis WJ, Koh TJ: Blocking interleukinlbeta induces a healing-associated wound macrophage phenotype and improves healing in type 2 diabetes. Diabetes 2013, 62: $2579-2587$

30. Sindrilaru A, Peters T, Wieschalka S, Baican C, Baican A, Peter H, Hainzl A, Schatz S, Qi Y, Schlecht A, Weiss JM, Wlaschek M, Sunderkotter C, Scharffetter-Kochanek K: An unrestrained proinflammatory M1 macrophage population induced by iron impairs wound healing in humans and mice. J Clin Invest 2011, 121:985-997

31. Weisberg SP, McCann D, Desai M, Rosenbaum M, Leibel RL, Ferrante AW Jr: Obesity is associated with macrophage accumulation in adipose tissue. J Clin Invest 2003, 112:1796-1808

32. Saeed AM, Duffort S, Ivanov D, Wang H, Laird JM, Salomon RG, Cruz-Guilloty F, Perez VL: The oxidative stress product carboxyethylpyrrole potentiates TLR2/TLR1 inflammatory signaling in macrophages. PLoS One 2014, 9:e106421

33. Yang L, Di G, Qi X, Qu M, Wang Y, Duan H, Danielson P, Xie L, Zhou Q: Substance P promotes diabetic corneal epithelial wound healing through molecular mechanisms mediated via the neurokinin-1 receptor. Diabetes 2014, 63:4262-4274

34. Moor AN, Vachon DJ, Gould LJ: Proteolytic activity in wound fluids and tissues derived from chronic venous leg ulcers. Wound Repair Regen 2009, 17:832-839

35. Liu Y, Min D, Bolton T, Nube V, Twigg SM, Yue DK, McLennan SV: Increased matrix metalloproteinase-9 predicts poor wound healing in diabetic foot ulcers. Diabetes Care 2009, 32:117-119
36. Lobmann R, Ambrosch A, Schultz G, Waldmann K, Schiweck S, Lehnert H: Expression of matrix-metalloproteinases and their inhibitors in the wounds of diabetic and non-diabetic patients. Diabetologia 2002, 45:1011-1016

37. Rayment EA, Upton Z, Shooter GK: Increased matrix metalloproteinase9 (MMP-9) activity observed in chronic wound fluid is related to the clinical severity of the ulcer. Br J Dermatol 2008, 158:951-961

38. Baum CL, Arpey CJ: Normal cutaneous wound healing: clinical correlation with cellular and molecular events. Dermatol Surg 2005, 31 : 674-686; discussion 86

39. Tieu BC, Lee C, Sun H, Lejeune W, Recinos A 3rd, Ju X, Spratt H, Guo DC, Milewicz D, Tilton RG, Brasier AR: An adventitial IL-6/MCP1 amplification loop accelerates macrophage-mediated vascular inflammation leading to aortic dissection in mice. J Clin Invest 2009, 119:3637-3651

40. Hinz B, Mastrangelo D, Iselin CE, Chaponnier C, Gabbiani G: Mechanical tension controls granulation tissue contractile activity and myofibroblast differentiation. Am J Pathol 2001, 159: $1009-1020$

41. Spenny ML, Muangman P, Sullivan SR, Bunnett NW, Ansel JC, Olerud JE, Gibran NS: Neutral endopeptidase inhibition in diabetic wound repair. Wound Repair Regen 2002, 10:295-301

42. Mangiafico S, Costello-Boerrigter LC, Andersen IA, Cataliotti A, Burnett JC Jr: Neutral endopeptidase inhibition and the natriuretic peptide system: an evolving strategy in cardiovascular therapeutics. Eur Heart J 2013, 34:886-893c 